\title{
Evaluation of a capnodynamic method for monitoring effective pulmonary blood flow in an ischemia and reperfusion porcine model
}

Thorir Sigmundsson ${ }^{1,2}$, Caroline Hällsjö Sander ${ }^{1,2}$, Tomas Öhman ${ }^{1}$, Magnus Hallbäck ${ }^{3}$, Håkan Björne ${ }^{1,2}$ ${ }^{1}$ Department of Anaesthesiology, Surgical Services and Intensive Care Medicine, Karolinska University Hospital, Solna, Sweden 2Department of Physiology and Pharmacology, Karolinska Institutet, Stockholm, Sweden

3Maquet Critical Care AB, Solna, Sweden
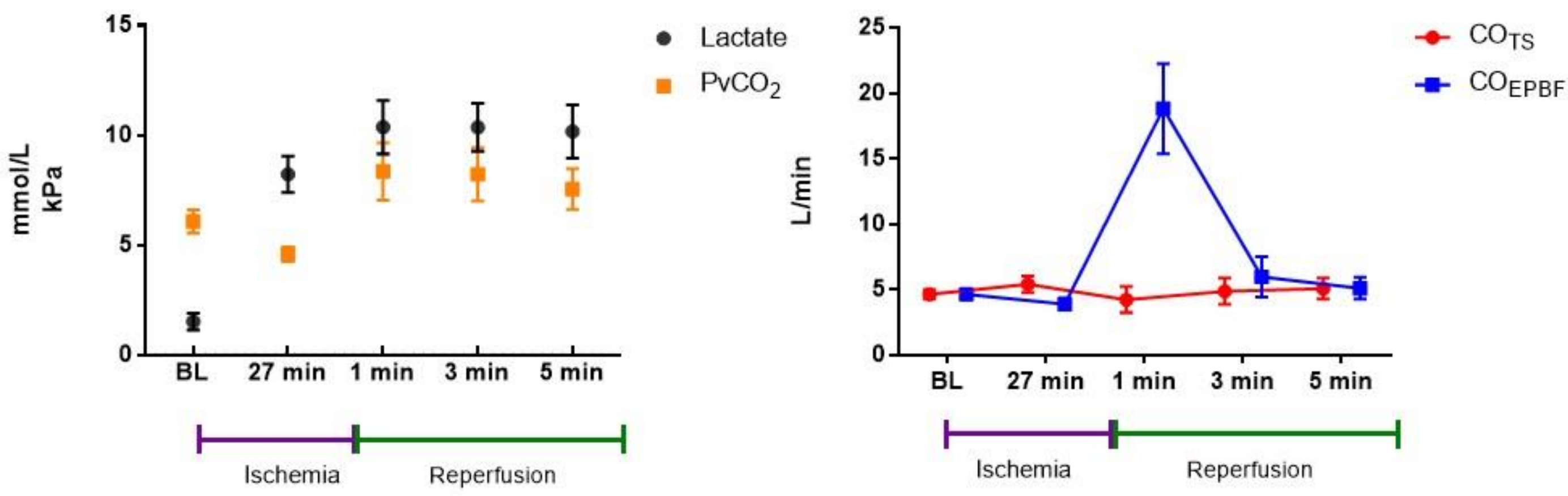

\section{Introduction}

A capnodynamic equation can be used to calculate effective pulmonary blood flow $\left(\mathrm{CO}_{\mathrm{EPBF}}\right)$ i.e. cardiac output (CO) minus shunt. ${ }^{1}$ An ischemic injury with subsequent reperfusion increases the concentration of carbon dioxide temporarily, a situation that theoretically could affect the agreement of a capnodynamic method.

The aim of the current study was to evaluate $\mathrm{CO}_{\text {EPBF }}$ during rapid changes in $\mathrm{PvCO}_{2}$ in an ischemia and reperfusion porcine model.

\section{Methods}

A ventilatory pattern containing cyclic reoccurring expiratory holds was used to create the required alterations of alveolar carbon dioxide concentration and the mathematical model used to calculate $\mathrm{CO}_{\mathrm{EPBF}}$ assumed a steady state in $\mathrm{PvCO}_{2}$ levels.

$\mathrm{CO}_{\text {EPBF }}$ was compared to a reference method for $\mathrm{CO}$, an ultrasonic flow probe around the pulmonary trunk in eight pigs.

A 10 Fr Reliant catheter (Medtronic) was placed in the aorta below the diaphragm via the femoral artery and inflated until blood flow in the contralateral femoral artery was abolished according to ultrasound doppler. Hemodynamic measurements, lactate levels and $\mathrm{PvCO}_{2}$ were obtained at baseline before balloon inflation, at minute 27 of ischemia and after deflation at minute one, three and five during reperfusion.

\section{Results and discussion}

The ischemic model resulted in significant changes in lactate and $\mathrm{PvCO} 2$ levels from baseline 1.5 $\mathrm{mmol} / \mathrm{L}(1.2-2.4)$ and $8,5 \mathrm{kPa}(7.2-11.4)$ to 8.2 $\mathrm{mmol} / \mathrm{L}(7.2-9.0)$ and $5.2 \mathrm{kPa}(4.1-6.2)$ at minute 27 of ischemia and $10.4 \mathrm{mmol} / \mathrm{L}(7.8-11.4)$ and 10.7 $\mathrm{kPa}(9.0-12.3)$ at minute one after deflation. Bland Altman plot at baseline showed bias $0.7 \mathrm{~L} / \mathrm{min}$, limits of agreement (LoA) $-0.2-1.6 \mathrm{~L} / \mathrm{min}$ and a percentage error (PE) 22\%. At minute five bias was $0.02 \mathrm{~L} / \mathrm{min}$, LoA $-1.8-1.8 \mathrm{~L} / \mathrm{min}$ and PE $36 \%$.

\begin{tabular}{|r|c|c|c|}
\hline $\begin{array}{l}\text { Bland Altman } \\
\text { analysis }\end{array}$ & Bias & LoA & PE \\
\hline Bscheline & 0.7 & -0.2 to 1.6 & $22 \%$ \\
\hline Reperfusion $\mathbf{1}$ min & 14.6 & 7.9 to 21.3 & - \\
\hline Reperfusion 3 min & -1.5 & -3.0 to 0.0 & $34 \%$ \\
\hline Reperfusion 5 min & 0.02 & -2.5 to 4.7 & $68 \%$ \\
\hline
\end{tabular}

\section{Conclusion}

$\mathrm{CO}_{\text {EPBF }}$ recuperates fast after rapid changes in $\mathrm{PvCO}_{2}$ resuming acceptable levels of agreement in 5 minutes. 